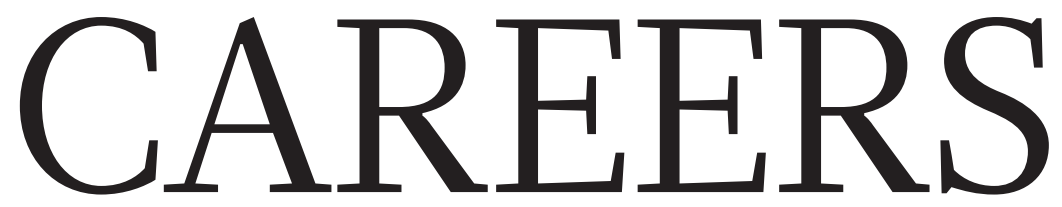

@NATUREJOBS Follow us on Twitter for the latest on science jobs go.nature.com/e492gf
NATUREJOBS BLOG Hot science-careers news and tips go.nature.com/lelkkf
NATUREJOBS For the latest career listings and advice www.naturejobs.com

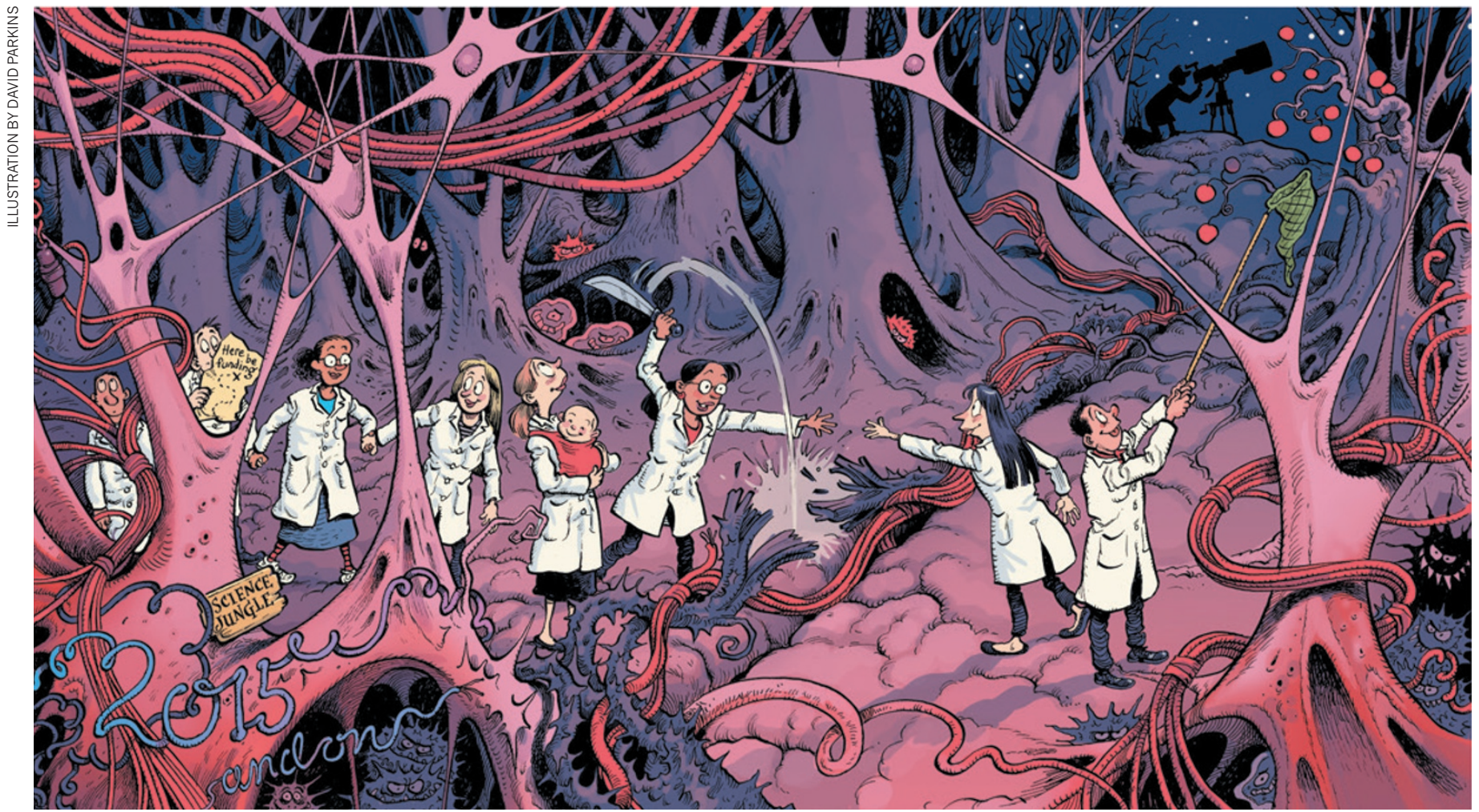

\title{
Hopes for the year ahead
}

To kick off 2015, Nature's Careers section asked several young scientists - all 40 or under - about their plans for the year ahead and their wishes for the future of science.

\section{FIND THE FRONTIER}

Óscar Fernández-Capetillo, 40, wants to find what causes a type of DNA damage that is linked to cancer and ageing. A group leader at the Spanish National Cancer Research Center in Madrid, he survived a serious motorbike accident last year. He also developed an easy way to find genes that help cancers to resist chemotherapies.

My New Year's resolution is to travel less. Enough of one-night stays in beautiful cities that I only get to see through the window on the taxi ride! I want time to study organic chemistry - my future life seems to be linked to drug development, and I want to understand the language of my chemist colleagues. I have bought plenty of books from Amazon and they are sitting on my desk, looking at me. But first I have to travel less.

Normal mammalian cells have two copies of each gene, so even if you mutate one copy you still have the other, and the efficiency of screening for gene function is severely reduced. Now we can screen mammalian cell lines that stay haploid, and contain just one copy of each gene. This has been like a quantum leap for us. We are looking for routes of resistance to cancer drugs and trying to understand how DNA repair genes work. Now

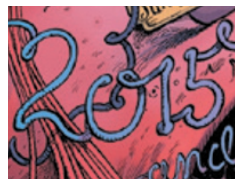

ONATURE.COM

Tweet your own plans and hopes at \#scihopes 15

For more responses:

go.nature.com/6jgyce that we have these screening platforms, I am happy to test anything that comes to mind.

My personal hope is that something amazing will happen that I cannot predict today and that will keep my mind busy for another 5 or 6 years. If I can tell you what I'll be doing in 5 years then it's pretty boring.

My hopes for science are that we evolve a little bit and identify scientists not from their papers but as individuals. In Europe, the system is very bureaucratic - they want you to tell them every step that you will be taking in the next five years: 'I'm going to construct a bridge, and by 2016 I'll have the first wall'. If you know where you're going, it's not science. Frontier science means that you are lost, that you are exploring, that you don't know what you'll get at the other end. 
Lab-wise, I want to surround myself with colleagues who, when talking science, come up with questions that start with "Why don't you...", rather than "Why did you..." Destructive egos are OK to add control to your experiment. Constructive people move the world forward.

\section{LOVE KNOWLEDGE}

Last year, structural biologist Nieng Yan, 37, at Tsinghua University in Beijing, China, used crystallography to solve the structure of a protein that brings essential fuel into cells and that scientists have been studying for more than $\mathbf{4 0}$ years.

I want to go to more places. I like to travel with my parents, so I would like to bring them to see the world. They are in their $60 \mathrm{~s}$, and it is the right time for them: they don't need to worry about finances and they are strong enough to walk long distances. Next year, I will see New Zealand and Australia. I'm a big fan of Lord of the Rings and the Hobbit.

We're at the best and worst time for structural biology. We crystallize molecules and use $\mathrm{x}$-rays to get diffraction patterns that reveal their structure, but an approach called cryo-electron microscopy (cryo-EM) has undergone a revolution because of technological advances. Challenging projects that might have taken 10 years using crystallography take just half a year with cryo-EM. You have to wonder what you will do for the other nine years. I have this anxiety about what is next. I might need to restructure my lab to expand the lab's expertise or maybe go on sabbatical.

Everyone is always talking about translational research, but if you look back, it's always the basic research that is revolutionary. I don't want people to ask me, 'Can your research save our lives?' One of our aims is to benefit human beings, but basic research is really about revealing the facets of nature. Knowing something is very cool.

For science in general, I hope that people will no longer need to worry about funding so much. From principal investigators to

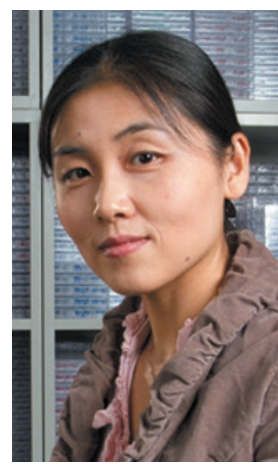

"It's always the basic research that is revolutionary." Nieng Yan graduate students, everyone is complaining about funding. I feel very sad about that. In China it's a little better; I am glad that people have begun to realize that economic growth will depend on science and technology.

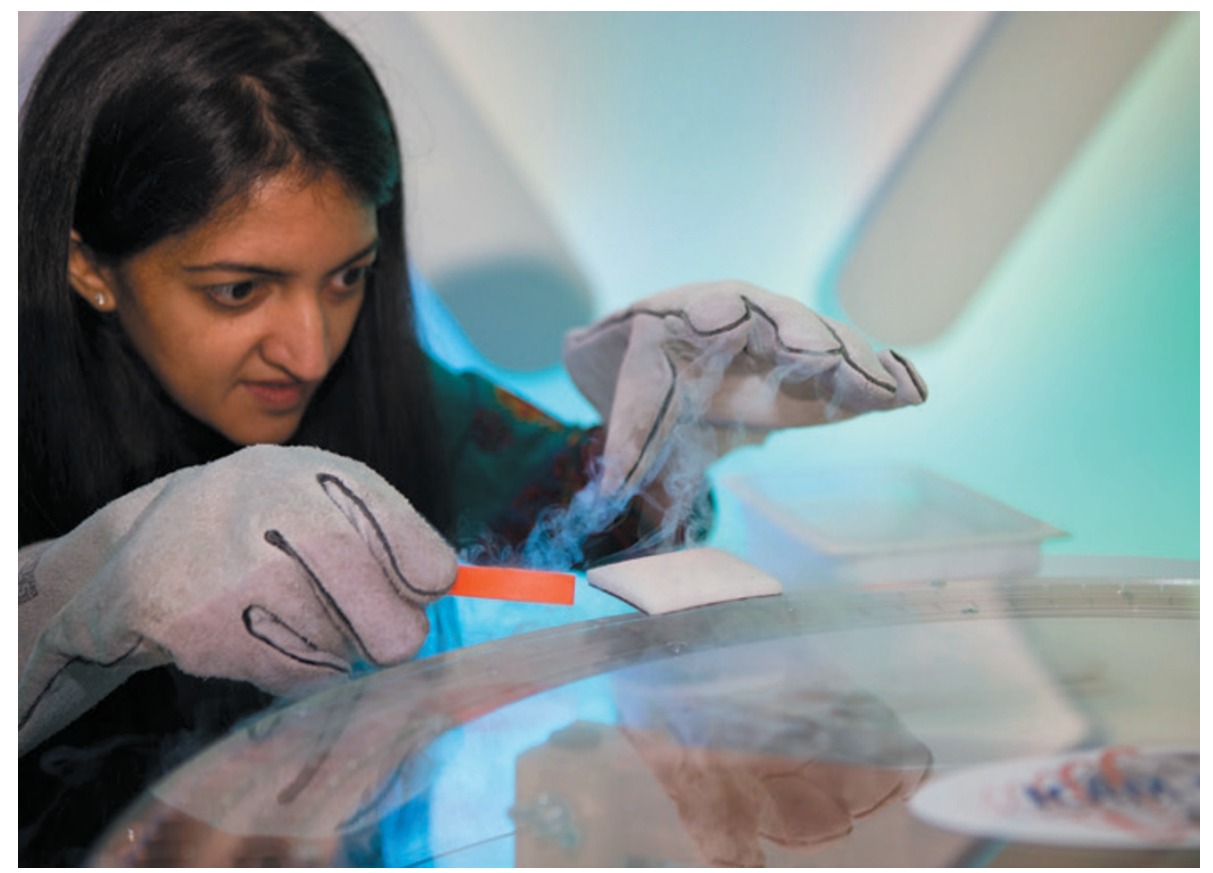

Suchitra Sebastian sometimes refers to herself as a "quantum alchemist".

\section{REACH FOR HIGH-HANGING FRUIT}

Materials scientist Jen Dionne, 33, at Stanford University in California has developed a technique to visualize how light interacts with materials at the nanometre scale. Last year she gave birth to her first child and won a Presidential Early Career Award for Scientists and Engineers.

Having a baby changes your perspective - you want to work on advances that can truly make the world better for the next generation.

As a new mom, I've needed to devise alternate strategies for striking a work-life balance. I'm hoping that the schedule structure imposed by a newborn will make me more productive in lab when I'm on campus, and better able to execute writing tasks when my baby is sleeping. When given just a few hours to work on a paper or proposal, focusing quickly is key.

As a child, I remember seeing the iridescent wings of the blue morpho butterfly, and learning how their colour emerges not from pigments but from how light interacts with the microscopic structure of transparent materials. These beautiful natural examples probably drove my interest in engineering materials that interact with light in precise ways. Next year, I'm eager to experimentally demonstrate nanostructured materials in which photons travel in just one direction. Devices today - from mobile phones to supercomputers - rely on electronic components, partly because it's easy to use these to make electrons go one way. Replacing electronic components with optical ones could make technology smarter, smaller and more energy efficient.

My hope for the scientific community is that budding scientists aren't afraid to pursue research that they are genuinely interested in and enthusiastic about.

There's a quote by author Jack Kerouac: "The only people for me are the mad ones, the ones who are mad to live, mad to talk, mad to be saved, desirous of everything at the same time." I hope that scientists can find what makes them "mad to live" and to plan their careers accordingly. I would advise them not to be afraid to reach for the high-hanging fruit, and to maintain their passion for discovery amid the daily challenges that come with being a scientist.

\section{SOLVE PROBLEMS IN NETWORKS} Bioengineer Danielle Bassett, 33, at the University of Pennsylvania in Philadelphia, last year won a MacArthur 'Genius' grant. She uses network science to understand the human brain.

Ahead for 2015 is to get more sleep. With a newborn and a 3-year-old, sleep is hard to come by. Also, I want to have a bowl of chocolate on my office table that is consistently filled up, because creative scientific thought is always better with chocolate!

I also want to explore applying tools from systems engineering to medicine, asking how drugs or electromagnetic stimulation could help those with mental-health problems or brain injuries. The big questions lie at the intersection between systems engineering and neuroscience. How do brains work as networks, and how does that shape understanding?

To enable more discoveries, more scientists need to spend time together. Instead of organizing single-discipline conferences, we need more interdisciplinary calls to work on a problem area, to increase the conversations about problems. How should we quantify the neurobiological effects of the learning 

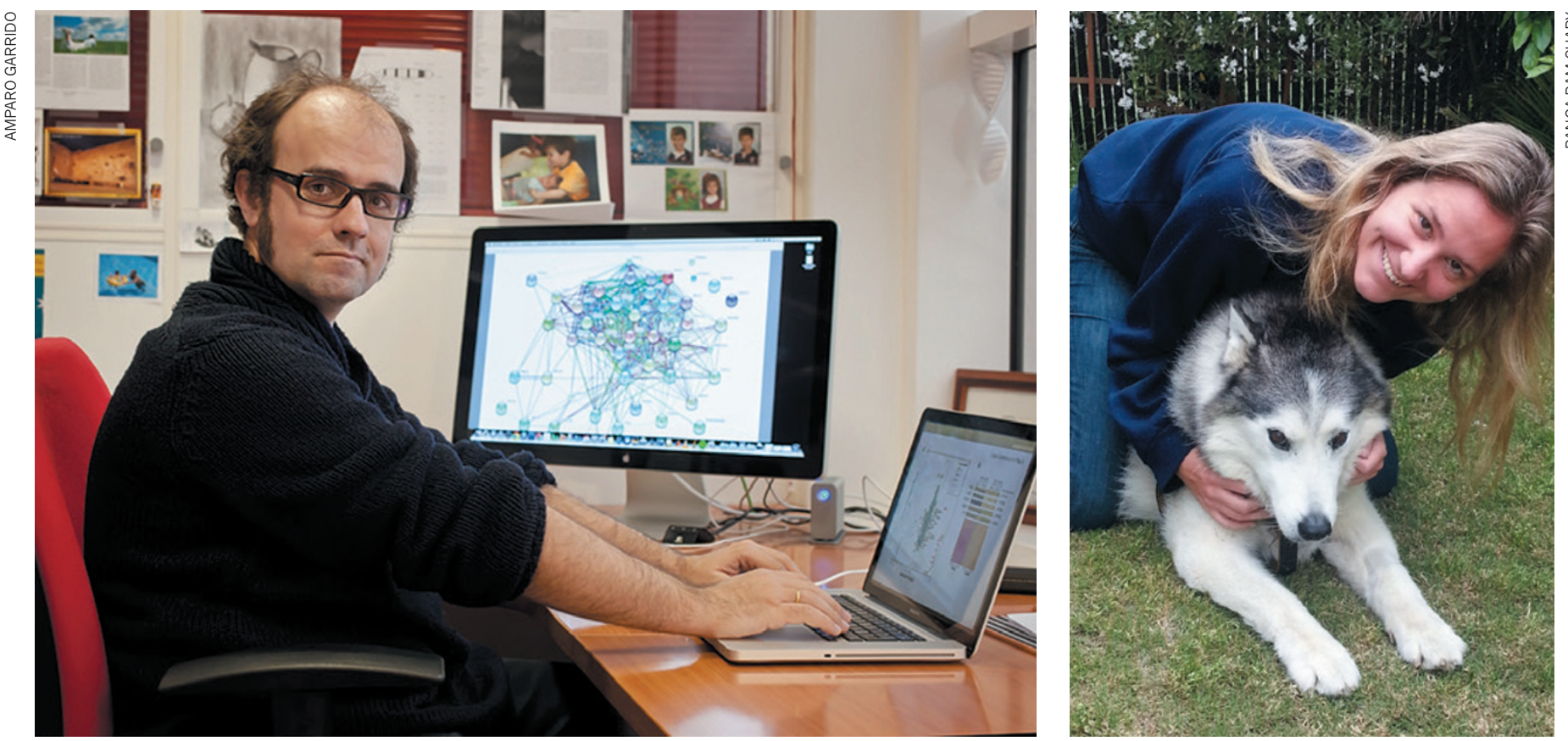

Óscar Fernández-Capetillo wants to surround himself with constructive thinkers, and Hilke Schlichting wants to encourage small-group discovery.

environment - for instance, a classroom - if we want to have a translational or societal impact? If we all got together and thought about that, we could come up with new directions.

\section{PLAN FOR DISCOVERY}

Physicist Suchitra Sebastian, 38, searches for materials that could revolutionize energy transport and storage at the University of Cambridge, UK. Last year, she was listed as one of thirty exceptional young scientists by the World Economic Forum. She sometimes refers to herself as a 'quantum alchemist'.

I do live theatre, mostly comedies, and I want to make that more frequent this year. Physics can be isolating; you are constantly thinking. I do theatre because that takes you out of your head - you have to connect with people, the actors, the audience.

In my lab this year, we want to find superconductors that can work without being chilled to impractically low temperatures. We grow highpurity crystals from materials that we think are on the brink of superconductivity, then subject them to very high pressures with diamond anvils - the tips of the diamonds apply pressure in a similar way to a stiletto heel. If we push them a little bit, the electron organization in the material will tip over and become a superconductor, a material that can carry electricity with no loss of energy. It's like taking dust and making it into gold.

For the science community, I think we should focus more on the process of discovery. To make a discovery, you have to be willing to take risks and to be wrong some of the time. But the current culture of science rewards you more for being incremental, for not being wrong. Although the incremental work is crucial, the field is skewed towards it. Creativity and discovery should be equal goals.

\section{CROSS DISCIPLINES}

Trained in biomedical and electrical engineering, Christine Hendon, 31, at Columbia University in New York is working out ways to monitor beating hearts at the scale of cells or even smaller. Last year she won a New Innovator Award from the US National Institutes of Health.

I've just had my first child. It will be hard to manage conferences and travel, so my goal is to find conferences on the East Coast.

A specific goal for us is to use a device that we developed this year in explanted hearts and to demonstrate it in hearts functioning within the body. Most imaging techniques give you an idea of how the tissue looks, but when you are making a medical decision, you want to know how it functions. We want to fill in gaps in medical imaging by correlating structure with function. Then we can address clinical problems - monitoring arrhythmia or electrical abnormalities in the heart - for which ultrasound is ineffective.

If I had a hope for the scientific community, it would be to break down disciplines, to encourage students to take classes outside of their departments. For a lot of applied work, you need to work in groups. And you need a good understanding of both your own discipline and those of your collaborators. So it's good not to associate yourself only with electrical engineers or only with biologists.

Not everyone views cross-training as valuable - it means longer training times - but when you are working in these large groups on big problems, you're really effective only if you can communicate with your collaborators.
MAKE SPACE FOR SMALL GROUPS Astrophysicist Hilke Schlichting, 32, at the Massachusetts Institute of Technology in Cambridge believes that learning how planets form is the first step in learning where we come from and how likely life is to happen.

I want to work a bit less and to spend more time with my husband and Alaskan malamute, Makalu, named after the fifth-highest mountain in the world. We have already made plans to go to Indonesia, Namibia and Tanzania together.

The big question for my lab right now is trying to understand how a newly discovered class of planets formed. The Kepler space observatory, which NASA launched in 2009, has found more than 4,000 candidate planets around other stars. It has found planets with orbits that are smaller than Mercury's and that circle their suns in 10-30 days or even fewer. Nothing like them is found in our Solar System. I want to know if these planets formed close to where we see them today or in larger orbits that moved inwards.

In terms of the future, it is getting harder and harder for people to do work in small groups that are not tied to consortia. We need to keep the diversity and independence of small research groups, particularly for junior faculty members.

There is funding for missions; people make small contributions to big missions, and that's important, but we still need to make sure that we have independent lines of inquiry. Theoretical research is generally done in small groups. I hope that we will be able to maintain that. SEE COMMENT P.15

From interviews conducted and edited by Monya Baker. 